\title{
Algumas palavras em agradecimento a Jeremy Whitehand
}

\author{
Karin Schwabe Meneguetti (1)
}

Universidade Estadual de Maringá, Maringá, PR, Brasil.E-mail: ksmeneguetti@uem.br

O ano de 2021 está sendo particularmente difícil para todos nós, soma-se às incertezas da pandemia e à mudança dos hábitos de vida a perda de pessoas preciosas. Em nosso mundo acadêmico, perdemos Silvio Macedo no início do ano e agora Jeremy Whitehand. Junto-me ao coro dos novos órfãos da morfologia urbana inglesa, pesarosos pela falta de nosso maior expoente, mas gratos pelas lições que sua presença entre nós deixou.

A ciência avança pelo esforço de seres humanos dedicados, intelectualmente iluminados e cientes do seu papel no desenvolvimento das ideias. Nesse último ponto, a humildade em se fazer entender e transmitir seu conhecimento para educar e fazer os estudos progredirem é fundamental. E era exatamente assim que o Professor Whitehand se colocava: apesar da bagagem acumulada, ouvia e discutia ideias com generosidade e gentileza. Um 'gentleman'.

Não podemos falar em morfologia urbana sem citar os trabalhos do Professor Whitehand. Se M. R. G. Conzen foi o início, adaptando e ilustrando conceitos, e assim fundamentando a escola inglesa, Jeremy Whitehand foi o responsável por desenvolver, refinar e disseminar a escola. Sua obra está evidenciada no livro editado por Vitor Oliveira (2019), J.W.R. Whitehand and the Historico-geographical Approach to Urban Morphology, e seus textos listados pela Universidade de Birmingham (2021).

Figura incansável nos encontros do ISUF, na editoria da revista, juntamente com sua mulher, Susan, e na orientação de muitos que hoje se utilizam da morfologia em seus estudos e trabalhos.

Para ilustrar sua generosidade com a disseminação do conhecimento, tão rara em nosso meio, vou apresentar a minha experiência. Não tive o Prof. Whitehand - ou simplesmente Jeremy, para aqueles que convivemos com ele - como professor, orientador ou qualquer outro vínculo formal, mas tive o prazer de poucos, mas importantes, contatos.

Começamos a participar dos eventos do ISUF em 2005, em Londres, meu colega Renato Leão e eu. Recebi a informação por meio do e-mail da USP, onde eu fazia meu doutorado na época. Enviamos nosso trabalho, tomamos coragem e fomos. Nesse evento conhecemos Vitor Oliveira e dividimos a seção com as apresentações de Staël Pereira Costa e de Silvio Macedo (com os quais viríamos a estabelecer vínculos por meio da rede de pesquisa QUAPASEL), e nos encantamos com as pesquisas e personagens desse grupo do ISUF.

Em 2007, no ISUF em Ouro Preto, após minha apresentação, Jeremy veio conversar comigo no café e me ofereceu de publicar nosso trabalho na Urban Morphology. Seria o primeiro de uma relação frutífera de publicações sobre a colonização no Norte do Paraná, o conjunto de cidades e a forma dos núcleos urbanos (Rego e Meneguetti, 2008, 2010; Rego, 2014).

No ISUF de 2011, em Montreal, apresentei minha aplicação em Maringá de um fenômeno no qual Jeremy era expert - as faixas de hiato urbano, ou urban fringe belts. Era uma pesquisa derivada de uma dissertação de mestrado que eu orientara e Jeremy não só prestou atenção, como pode ser visto na Figura 1, mas fez contribuições brilhantes que me incentivaram a me aprofundar no tema, vendo potencial onde eu mesma não acreditava muito.

A partir daquelas observações, procurei a Prof ${ }^{a}$ Staël de Alvarenga Pereira Costa, a principal pesquisadora da escola inglesa no Brasil, para esmiuçar a teoria dos fringe belts e adaptar às novas cidades brasileiras, cunhando o termo 'faixa de hiatos urbanos' no Laboratório da Paisagem da Universidade Federal de Minas Gerais. Novamente o feedback do Jeremy foi fundamental, e o resultado está publicado na Urban 
Morphology (Meneguetti e Pereira Costa, 2015).

Seguimos conversando sobre as aproximações da morfologia urbana com a ecologia urbana e a infraestrutura verde, minhas áreas de atuação. Novamente quero destacar a capacidade do Prof. Whitehand de contínua evolução, incorporando novas possibilidades da morfologia em face dos desafios globais, como pode ser visto nos seus textos recentes, por exemplo, sobre espaços verdes e sustentabilidade (Whitehand, 2019), e a relação da morfologia urbana com a ecologia (Whitehand, 2018), provocando pesquisadores para a evolução dos conceitos e metodologias que ele consolidou.

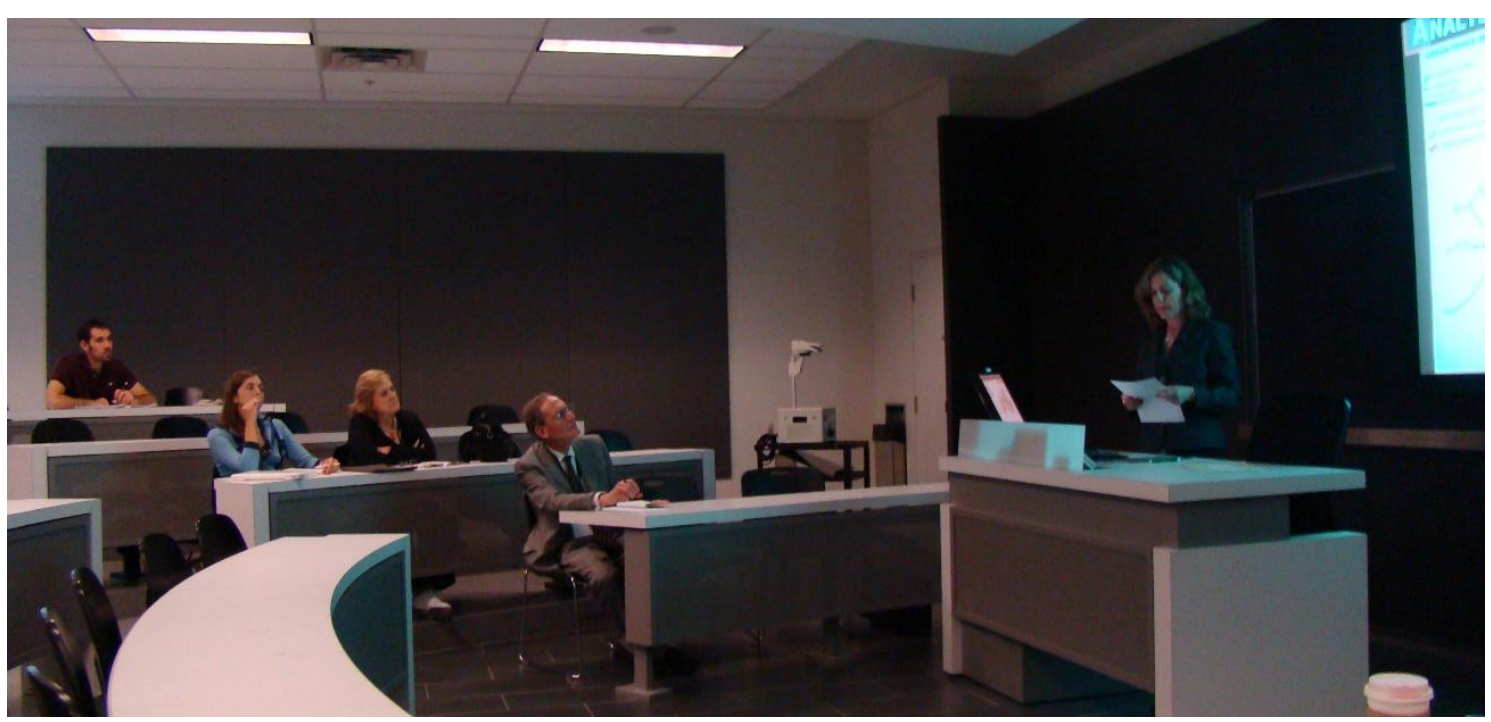

Figura 1. ISUF 2011 - Montreal. Jeremy Whitehand na primeira fila do auditório (foto da autora).

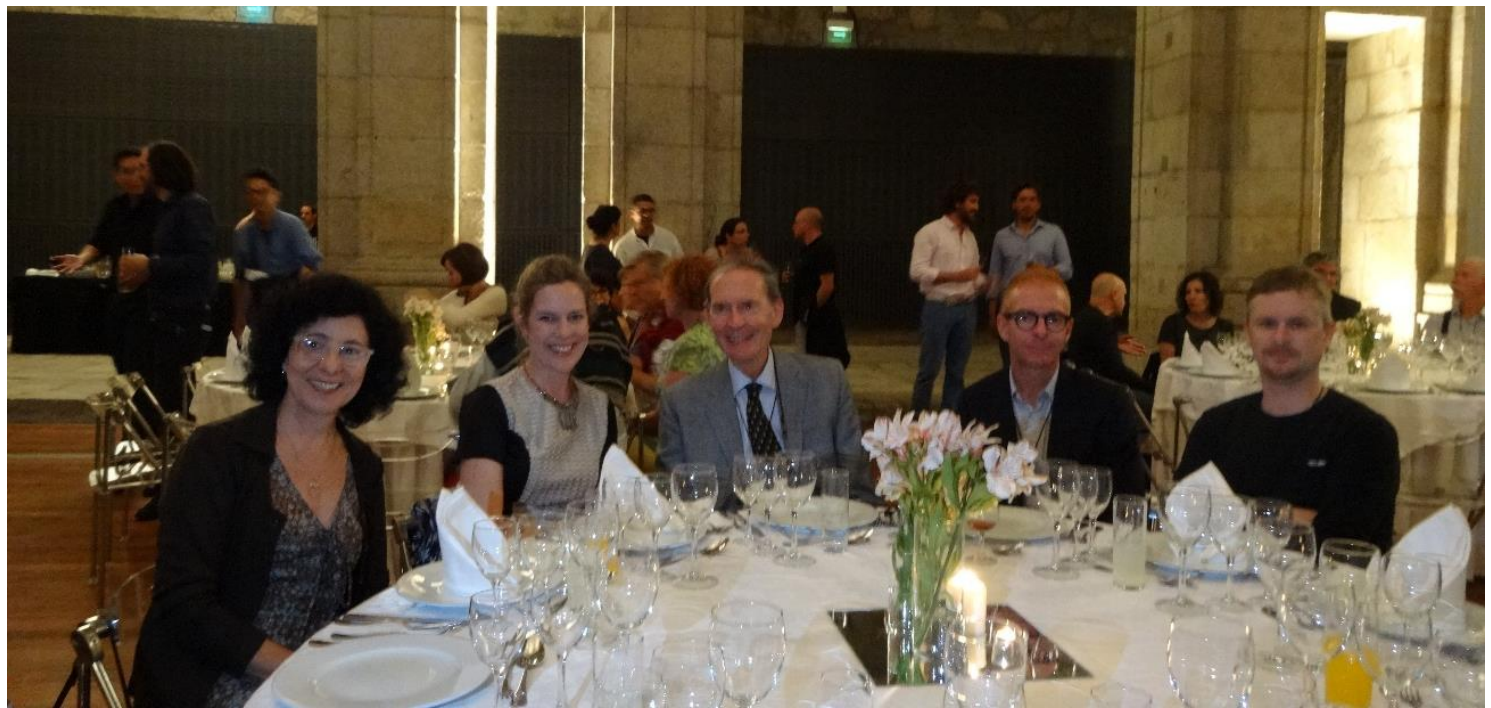

Figura 2. ISUF 2014 - Porto, jantar de gala. Eneida Mendonça, eu, Jeremy Whitehand, Renato Leão e Ian Morley (foto da autora).

Poderia falar muito sobre Jeremy Whitehand, sobre seu trabalho fundamental, sobre as pessoas que ele formou e hoje têm papel relevante na pesquisa, sobre a árdua tarefa de disseminação do conhecimento em seminários, publicações, entrevistas, etc. Lembramos, na sessão de homenagem a ele no encerramento do PNUM 2021, de alguns fatos importantes, mas para mim, essencial é o exemplo de caráter.

É a lição que fica. 


\section{Referências}

Meneguetti, K. S. e Pereira Costa, S. A. (2015) The fringe-belt concept and the planned new towns: a Brazilian case study. Urban Morphology. 19 (1), 25-34.

Oliveira, V. (ed.) (2019) J.W.R. Whitehand and the Historico-geographical Approach to Urban Morphology. Switzerland, Springer International Publishing.

Rego, R. L. e Meneguetti, K. S. (2008) British urban form in twentieth-century Brazil. Urban Morphology. 12 (1), 25-36.

Rego, R. L. e Meneguetti, K. S. (2010) Planted towns and territorial organization: the morphology of a settlement process in Brazil. Urban Morphology. 14 (2), 101-109.

Rego, R. L. (2014) The new urban form and the model city: town planning in the Brazilian hinterland. Urban Morphology. 18 (1), 59-68.
University of Birmingham - Research Portal. Disponível em:

https://research.birmingham.ac.uk/portal/en/p ersons/jeremy-whitehand(684dff13-a0c74762-8984-430cbca6d7c4)/publications.html. [Consultado em 10 de julho de 2021].

Whitehand, J. W. R. (2018) Editorial comment. Crossing boundaries: towards a more integrated approach? Urban Morphology. 22 (2), 99-100.

Whitehand, J. W. R. (2019) Green space in urban morphology: a historico-geographical approach. Urban Morphology. 23 (1), 5-17. 